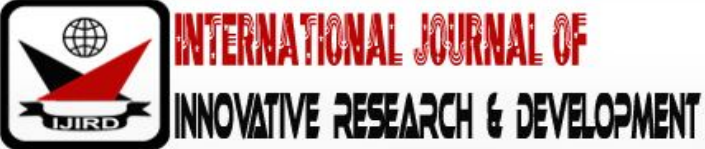

ISSN 2278 - 0211 (Online)

\section{Senior High Schoolers' Atitudes toward Visual Art Education in Ghanaian Secondary Schools}

\author{
Dr. Moro Ismaila \\ Lecturer, Department of Communication Design, \\ Kwame Nkrumah University of Science \& Technology, Kumasi, Ghana \\ Eric Francis Eshun \\ Senior Lecturer, Department of Communication Design, \\ Kwame Nkrumah University of Science \& Technology, Kumasi, Ghana
}

\begin{abstract}
:
This research aims at studying senior high school students' attitudes toward visual art education in terms of a) their gender, b) their level in education, c) the location of school. The current research was conducted with sample of 385 students selected from six senior high schools located in both urban and peri-urban precincts in Ashanti Region of Ghana in the 2015-2016 academic years. A perspectives scale of 50items was employed so as to obtain the data required. The alpha reliability for the scale of perspectives toward visual art education was found to be 0.766 . The t-test was used in the comparison of pairs whereas one directional variance analysis and Scheffe test was used in comparing groups larger than pairs in data analyses. In consequence, the statistical data demonstrated that senior high school visual art students' perspectives towards visual art education did not differ on the basis of a) gender and b) education level, however, significant difference existed between those located in the peri-urban and urban communities.
\end{abstract}

Keywords: Senior high school, visual art education, perspectives towards visual art

\section{Introduction}

Art, is the product of human creative activity in which materials are selected and shaped to convey an idea, emotion, or visually interesting form especially within the graphic arts or visual arts including other forms of creative activity, such as dance, drama, and music. By and large the visual art is the bedrock of the creative industries that are changing peoples' life. Creative Scotland (2014) postulates that "the creative industries shape, and make, a significant contribution to our culture, communities and economy. They improve how we live, learn, work and participate. They generate income, employment in the creative economy and often act as a catalyst for regenerating places". Thus, for an interest in visual art studies to be rewarding and beneficial to pursue, first of all, visual art students need to have an indepth understanding and appreciation for the visual art discipline. The purpose of this study is to examine the perspectives of prospective visual art students' outlooks on visual art education.

\section{Literature Review}

\subsection{Visual Art Education}

Visual art has become an important component of school curricula across the world (Fleming, 2010). NACCCE report "All Our Futures" in 1999 cited in Fleming (2010) indicated that arts in curriculum provided for "developing a full variety of human intelligence (in contrast with academic study and logico-deductive thought); creative thought and action (for adaptability); education of feeling and sensibility; exploration of values; understanding cultural change and differences; developing physical and perceptual skills". Many studies on Visual art education have been conducted around the world by researchers such as Watts, 2005; Alter, Hays, \& O'Hara, 2009; and Indoshi et al., 2010. A review of their literatures has shown that Visual art education is sidestepped in relation to logico-deductive reason and for propositional knowledge (Steers, 2011) and time and quantity of subject matter in primary learning and development considered as "over-crowded curriculum" (Alter, Hays, \& O’Hara, 2009; Indoshi et al., 2010). Several studies, especially those conducted by Indoshi et al., (2010), have simultaneously investigated environmental, administrative and curriculum related factors on visual art education. Alter et al. (2009) and Of STED (2013) discussed at length challenges with teacher preparation towards the teaching of creative arts at basic level of education.

A study by Dr. Eulalee Nderu-Boddington (2008) on Arts Education and Student's Perception found out that some countries are restructuring their art programmes. Sweden, for instance, is restructuring its art programmeto it an essential component for developing student wellbeing for the job market (Lindstrom, 1997). Japan, on the other hand, has 
incorporated the arts in its curricula, which emphasizes on craftsmanship in school to cultivate excellence in the workplace. The teaching of expressive arts in the schools, particularly at the elementary level, has enabled the Japanese society to develop greater tolerance, problem-solving skills, and an appreciation for aesthetics, creativity, and decisionmaking in its students (Lindstrom, 1997).Some researchers also claim that arts revitalize neighbourhoods and promote economic prosperity (Costello 1998; SCDCAC 2001; Stanziola 1999; Walesh 2001). Participation in the arts improves physical and psychological well-being (Baklien 2000; Ball and Keating 2002; Bygren, Konlaan and Johansson, 1996; Turner and Senior 2000). The arts provide a catalyst for the creation of social capital and the attainment of important community goals (Goss, 2000; Matarasso, 1997; Williams, 1995). In spite of the numerous studiesin the arts, there is no study on the direct relationship between perspectives from art students in peri-urban and urban communities.

\subsection{Visual Art Education in Ghana}

The introduction of visual art into Ghanaian education system faced some initial challenges. Edusei (2004) recounted the history of the re-introduction of formal Art in Ghana's education system in 1919, after it was abandoned by the Christian Missionaries who setup and ran the mission schools in Ghana at the beginning of 20th century.Ross (2004), like Edusei (2004), sharpened and extended some important points about visual arts in Ghanaian education system. She observed thatthe artspermeate every aspect of Ghanaian culture and environment. However, sheidentifiedthree major challenges in thevisual art education in Ghana:(a) Western education and science, (b) commodification of traditional culture and (c) Christianity.

According to Edusei (2004) Ghanaian art and culture were considered fetish and primitive at the time by the Christian missionaries, hence, teaching art in their schools will invariable contravene the belief and practices of the new religion that was introduced in the mission schools. The conflict stems from the fact that African art products represented the beliefs, values and attitudes, as well as the history of the people and since the study of art develops appreciation of beauty in nature could increase the people's desire and love for their art and culture.

Although, the visual art education in Ghana has expanded to cover all levels of education in Ghana, yet, Ghanaians still have some reservations towards it. In one breath they appreciate and enjoy itsuse, in another breath despise it as a vocation, career or anti-Christianity. This attitude towards the visual art has transcended beyond controlled level. The decision to incorporate Visual Art into the curriculum of Ghanaian schools was worthwhile, among the rationale for teaching art goes further to include the production of high calibre professionals who will contribute to the development of the country in a wide variety of fields. However, results show that governments and officialdom pay lips service to thedevelopment of visual art (Source needed). It appears that anything to do with the visual art is considered by the powers that be as less important and can wait forever. No wonder, there are inadequate financial allocations to the schools for facilities, provision of art materials and inadequate professional art teachers teaching in at the primary levels. Preservice training in art education is lamentably inadequate. There is little or no recognition for Art teachers, no provision is made for Art teachers to improve their skills, andfew of them have personal skills in the arts (Okonkwo, 2014; I.N.T.O., 2009).

Although some researchers such as Ross (2004), Evans-Solomon \& Opoku-Asare (2011), have conducted studies on visual art education, their outcomes varied and were not conclusive.

\section{Objectives}

The present study investigates senior high school students' outlooks towards visual art education. To this end, the following research questions have been posed:

- Do the perception scores of the Senior High School students towards the visual art education differ significantly according to their gender?

- Do the perception scores of the Senior High School students towards the visual art education differ significantly according to their school location?

- Do the perception scores of the Senior High School students towards the visual art education differ significantly according to their level of education?

- Do the perception of influence scores of the senior high school students towards the visual art education differ significantly according to their location?

\section{Methodology}

This is a "descriptive" study aiming to examine visual art Senior High School students' outlooks towards visual art programme in terms of several variables.

\subsection{Sample}

The convenient sample group for this study comprised of 385 students enrolled in visual arts studies in 6 public senior high schools located in urban and peri-urban precincts in Ashanti Region of Ghana in the 2016 -2017 academic year.The sample group consists of 230 males (59.7\%) and 155 females (40.3\%) visual art students. The peri-urban group consists of 119 students (30.9\%) and the urban group consists of 266 students (69.1\%).

\subsection{Data Collection Instruments}

STIMULA developed by consortium of researchers from across Europeto measure post primary school pupil's perceptions toward science and technology was adopted in this study. This instrument has been widely used to measure perceptions related to the study of science and technology. STIMULA developed by Fraser (1981) originally consisted of 18 
scales and 123 items. In this study only six scales consisting of 50 items from the original form of STIMULA were selected and modified. They are adaptation to visual art attitudes, enjoyment of visual art lessons, leisure interest in visual art, perception toward science and technology, social influence and career interest in visual art. The perception scale used in this study consists of 50 items in 5-point Likert scale (Strongly Agree, Agree, Undecided, Disagree, Strongly Disagree). The alpha reliability was found to be 0.776 for the scale.

The data were obtained in the classroom and during school hours. Before the administration of the questionnaire,the consent of the school authority was sought, and the Class was addressed regarding the purpose and process of collecting the data. It was explained to them that the data would be used for quality assurance as well as for research purposes and will be treated with confidentiality. Therespondents' cooperation was requested,and they participated voluntarily. The tests were run in the various schools by Teaching Assistants who have received prior general training on how to apply the instrument. The study was conducted in the 2016 -2017academic year, from November to December.

\begin{tabular}{|c|c|c|}
\hline Variables & Items & Sampled Items \\
\hline $\begin{array}{c}\text { Attitude towards science and } \\
\text { technology }\end{array}$ & 7 & $\begin{array}{c}\text { "Improves your understanding of the things that affects you } \\
\text { and family" } \\
\text { "Improves your understanding of solving problems in your } \\
\text { daily life" }\end{array}$ \\
\hline Attitude towards visual art & 9 & $\begin{array}{c}\text { "My friends will be a strong influence on my choice of career" } \\
\text { "Visual arts subject are the most interesting to study at } \\
\text { schol" }\end{array}$ \\
\hline Visual art learning value & 12 & $\begin{array}{c}\text { "Visual arts are increasingly complicated" } \\
\text { "Visual arts are concerned with the needs of people" }\end{array}$ \\
\hline External Influences & 4 & $\begin{array}{c}\text { "My parents/ guardians will be a strong influence on my } \\
\text { choice of career" } \\
\text { "My friends will be a strong influence on my choice of career" }\end{array}$ \\
\hline "Tisual art as a career & 12 & $\begin{array}{c}\text { "Think is worthwhile" } \\
\text { "People who have career in visual arts are typically boring" }\end{array}$ \\
\hline
\end{tabular}

Table 1

\subsection{Data Analysis}

Data collected in this study was analysed by using the SPSS 16.0 software for processing and the results were computed in the form of frequency, arithmetic mean, standard deviation, t-test and one-way variance analysis were used for independent samples.

\section{Data Presentation and Results}

This study focuses on examining whether there was a significant different between the perspectives scores of the senior high school students and some characteristics they have. In the following presentation, the findings and comments are presented according to the sub problems.

5.1. Do The Perception Scores of the Senior High School Students towards the Visual Art Education Differ Significantly According To The Gender?

Independent samples t-test was done in order to determine whether there was a significant difference among the outlook scores of the students towards the visual art education according to their gender. The results were presented in Table 2.

\begin{tabular}{|c|c|c|c|c|c|c|c|}
\hline & Gender & $\mathbf{N}$ & Mean & SD & Df & t & p \\
\hline \multirow{2}{*}{ Outlook } & Male & 230 & 2.2998 & .37536 & 382 & -.996 & .320 \\
\cline { 2 - 5 } & Female & 154 & 2.3353 & .28478 & & & \\
\hline
\end{tabular}

Table 2: The t-test Results of the Perspectives Mean Scores of the Students According to the Gender

According to Table 2, the perception score of female students is $\mathrm{m}=2.3353$, while the score for male students is $\mathrm{m}=2.2998$. From the table, the mean perception score of female students is descriptively higher than the mean score of male students. However, the t-test results, show that the perception scores of female and male visual art students do not show any significant variation $(\mathrm{t}(382)=-.996 ; \mathrm{p}>$.05).

5.2. Do The Perception Scores of the Senior High School Students Towards the Visual Art Education Differ Significantly According to Their School Location?

The schools of the students who participated in the study were grouped as peri-urban and urban, according to their location, development and government administration. Independent samples t-test analysis was used in order to determine whether there was a significant difference among the outlook score distribution of the students in these groups. The results were presented in Table 3. 


\begin{tabular}{|c|c|c|c|c|c|c|c|}
\hline & Gender & N & Mean & SD & Df & t & p \\
\hline \multirow{2}{*}{ Perception } & Peri-urban & 230 & 2.172 & .3483 & 382 & -5.677 & .000 \\
\cline { 2 - 5 } & Urban & 154 & 2.378 & .3198 & & & \\
\hline
\end{tabular}

Table 3: The T-Test Results of the Perception Mean Scores of the Students According to the School Location

As shown in Table 2, the mean perception score of peri-urban schools' students has been determined to be $\mathrm{m}=2.172$, while the mean perception score of urban schools' students is $\mathrm{x}=2.378$. According to t-test result, it is understood that the mean perspectives scores of students in peri-urban and urban schools show significant variation $(t(382)=-5.677 ; p<05)$. This statistical difference is found to be in favour of urban school's visual art students.

5.3. Do The Perception Scores of the Senior High School Students Towards the Visual Art Education Differ Significantly According to Their Class?

The schools of the students who participated in the study were grouped according to their class. One-way variance analysis was used in order to determine whether there was a significant difference among the perception score of the students in these groups. The results were presented in Table 4.

\begin{tabular}{|c|c|c|c|c|c|c|}
\hline & $\begin{array}{c}\text { Source of the } \\
\text { Variance }\end{array}$ & SS & Df & MS & F & p \\
\hline $\begin{array}{c}\text { The Mean } \\
\text { Scores of the }\end{array}$ & Between Groups & .123 & 2 & .061 & \multirow{2}{*}{.523} & \multirow{2}{*}{.593} \\
\cline { 2 - 5 } Perception & Within Groups & 44.666 & 381 & .117 & & \\
\cline { 2 - 5 } & Total & 44.789 & 383 & & & \\
\hline
\end{tabular}

Table 4: The ANOVA Results of the Outlook Scores of the Students towards the

Visual Art Programme to the Class of the Students

According to Table 4, there was no significant difference among theperception scores of the classes(first, second and third year visual art students). When the perspectivesmean scores of the students were examined, it was observedthat the first-year students $(\mathrm{m}=2.350)$, second year students $(\mathrm{m}=2.321)$ and third year students $(\mathrm{m}=2.303)$ had mean scores that were close to each other. Although there was no statistically significant difference, it was striking that the mean scores of the first-year students was higher than the second and third year students.

5.4. Do The Perception of Influence Scores of the Senior High School Students towards the Visual Art Education Differ Significantly According to Their Location?

According to Table 5, score average of students' perceptions of external influence towards visual art programme is 2.56 for students wholive and have their education in peri-urban areas whereas it is 3.12 for those wholive and have their education in urban areas. The t-test result shows that there are significant differences between influence score averages. The findings obtained reveal that there are significant differences available between the groups interms of external influence towards visual art programme and that they demonstrated divergent influences.

\begin{tabular}{|c|c|c|c|c|c|c|c|}
\hline & Location & N & M & SD & Df & T & P \\
\hline \multirow{3}{*}{ Perception } & Peri-Urban & 119 & 2.5588 & .96205 & 383 & -4.746 & .000 \\
\cline { 2 - 5 } & Urban & 266 & 3.1047 & 1.07623 & & & \\
\hline
\end{tabular}

Table 5: the T-Test Results of the Perception Concerning Visual Art Students' External Influence towards Visual Art programme on the Basis of External Influences

\section{Discussion}

The findings show that majority of respondents agreed that parents/ guardians have strong influence and dictate on the type of career for their wards. These findings are in consistent with several studies done by educational researchers such as Knowles (1998); Marjoribanks (1997); Mau \& Bikos (2000); Smith (1991);Wilson \& Wilson (1992)and Khajehpour\&Ghazvini (2011). Middleton and Loughead (1993) examined three parental influences on children: positive involvement; non-involvement; and negative involvement. Their report indicated that parents who fell under positive involvement were enthusiastic about their children's career exploration and were very supportive of young adult's individual goals. The non-supportive parents were just unaware of what to do, how to help, or that their involvement is desired at all (Middleton and Loughead 1993). Also Analysing the responses of 5-14 year old students from families that were classified as middle-class or poor, Weinger (2000) found that those from middle class valued their parent's income, felt it would help them obtain their professional career, and saw themselves in similar professional roles as their parents.

The respondents' mindset about students pursuing visual art studies, which includes visual arts students are typically creative, work in a studio, competitive, hardworking, works in teams, genius, work both gender types, not boring, not nerdy and addicted to their work, were evident in this study. By and large most respondents showed appreciable understanding and appreciation of the discipline and were encouraged by the prospects in the profession to stay focus with their education. 


\section{Conclusion}

This study has been able to outline some mindset about people who pursue visual arts studies and most of these thoughts are positive. A number of negative factors, which affect students pursing visual arts, were observed in this study. These factors pose a great challenge to the profession and nation building. The respondents also have just little knowledge in the issues pertaining to visual arts since they are not exposed to visual arts exhibitions, field trips, experiments, speeches and competitions. Students are also not allowed to do more practical project to widen their knowledge scope. Moreover, it appears that students, teachers and parents lack education on the importance of visual arts in relations to the sciences and the businesses. These are important findings that should be considered in other to change the perception of students enrolled in the course in other to produce effective creative thinkers through the arts for the nation building.

\section{Recommendations}

The researchers make the following recommendations from the study:

- It is recommended that the findings of this study should be used by school authorities for planning, implementing and monitoring good critical analyses to help people understand visual arts issues, works and findings.

- Parents/guardians and school authorities should be educated on the importance of visual arts studies to the individual and the nation as a whole in a guidance form to help them make a good choice even in the branches and disciplines of arts.In addition, they should be educated on the importance of visual arts to the study of sciences and the businesses which they are more interested in.

- Adequate practical exercises in the various disciplines in the arts should be usedto broaden the scope of knowledge of students offering visual arts.

- Art teachers should be well trained in the visual arts and they should be compelled to use the designated curricula for visual arts in other to improve the outcome of arts for students.

- Senior High Schools offering Visual Art should collaborate visual arts institutions and create avenues for competitions, experimentations, research projects, speeches, field trips and exhibitions to boost the interest of Visual Arts students.

\section{References}

i. Alter, F., Hays, T. \& O'Hara, R. (2009). Creative Arts Teaching and Practice: Critical Reflections of Primary School Teachers in Australia. International Journal of Education \& the Arts. 10(9): 1-22.

ii. ASSOCIATIONS, C. O. (March 1991 reprinted in May 2009). An Overview of Health Issues for Performing and Visual Arts Students. briefing paper, 4-6.

iii. Ball, S. and Keating, C. (2002). "Researching for Arts and Health's Sake." in 2nd Conference on Cultural Policy Research. Wellington, NZ.

iv. Baklien, B. (2000). "Culture is Healthy." International Journal of Cultural Policy 7.

v. Bygren, L. O., Boinkum B. K. and Sven-Erik, J. (1996). Attendance at cultural events, reading books or periodicals, and making music or singing in a choir as determinants for survival: Swedish interview survey of living conditions." British Medical Journal 313:1577-1580.

vi. Costello, D. J. (1998). "The Economic and Social Impact of the Arts on Urban and

vii. Community Development." Pp. 1333-A in Dissertation Abstracts International, A: The

viii. Humanities and Social Sciences. Pittsburgh: University of Pittsburgh.

ix. Creative Scotland (2014). The Creative Industries. Edinburgh: Waverley Gate.

x. Duku, F. K. (2012). Pedagogic foundation of art education in Ghana. Arts and Design Studies, 4, 32-42.

xi. Edusei, K. (2004). An overview of visaul art education in ghanaian school. Journal of Science and Technology, 118.

xii. Evans-Solomon, F. \& Opoku-Asare, N.A. (2011). Girls' motivation, participation and preference for visual arts subjects in four senior high schools in Central Region, Ghana. Journal of Science and Technology. 31(3), 118-128.

xiii. Fleming, M. (2010). Arts in education and creativity: a literature review (2nd ed). Creativity, Culture and Education. London: Arts Council England.

xiv. Goss, K. (2000). Bettertogether: the report of the Saguaro Seminar on Civic Engagement in America. Cambridge, MA: Saguaro Seminar Civic Engagement in America John F. Kennedy School of Government Harvard University. http:/ / www.bettertogether.org/ bt\%5Freport.pdf.

xv. Guetzkow, J. (June 8, 2002). How the Arts Impact Communities. Taking the Measure of Culture Conference (pp. 810). Princeton University.

xvi. Indoshi, F. C.,Wagah, M. O. and Agak, J. O. (2010). Factors that determine students' and teachers' attitudes towards art and design curriculum. International Journal of Vocational and Technical Education. 2 (1): 9-17.

xvii. I.N.T.O. (2009). Creativity and the Arts in Primary School. Durblin: Irish National Teachers' Organisation.

xviii. Kevin F. McCarthy, Elizabeth H. Ondaatje, Arthur Brooks, András Szántó. (2005). Research in the arts. Santa Monica: RAND corporation.

xix. Khajehpour, M. and Ghazvini, S. D. (2011). Procedia Social and Behavioral Sciences. 15, 1204-1208

xx. Knowles, S. (1998). Effects of the components of parent involvement on children's educational and occupational aspirations. Unpublished doctoral dissertation, Alfred University, Alfred, New York.

xxi. Lartey, T. A. (2009). Different Strategies to Fostering Creativity in Visual Arts in Senior High School. GhanaKumasi: Department of General Arts Studies KNUST.

xxii. Lindstrom, L. (1997). Integrating creativity or communication? Paradigm shifts and continuity in Swedish art education. Arts Education Policy Review, 99(1): 1-17. 
xxiii. Marjoribanks, K. (1997). Family contexts, immediate settings, and adolescents' aspiration.Journal of Applied Developmental Psychology, 18: 119-132.

xxiv. Matarasso, F. (1997). Use or ornament?: the social impact of participation in the Arts. Stroud, Glos.: Comedia.

xxv. Mau, W. C. \& Bikos, L. H. (2000). Educational and vocational aspirations of minority and female students: A longitudinal study. Journal of Counselling and Development, 78: 186-194.

xxvi. McKewen, D. (2013). complicity and criticality in conteemporary art and fandom. the art of being a fan.

xxvii. Middleton, E. B. \& Loughead, T. A. (1993). Parental influence on career development. An integrative framework for adolescent career counselling. Journal of Career Development 19(3): 161-173.

xxviii. Nderu-Boddington, D. E. (2008). Arts Education and Student's Perception. Arts Education and Student's Perception, 3.

xxix. OfSTED (2009) 'Art (art, craft and design) survey visits', London, HM/ OfSTED.

xxx. Okonkwo, I. E. (2014). Towards Quality Art Education: Challenges and Opportunities. Unizik Journal of Arts and Humanities. 110-130. http:// dx.doi.org/ 10.4314/ ujah.v15i1.6

xxxi. Opoku-Asare, N.A., Tachie-Menson, A \& Essel, H. B. (2015). Perceptions, Attitudes and Institutional Factors that Influence Academic Performance of Visual Arts Students in Ghana's Senior High School Core Curriculum Subjects. Journal of Education and Practice, 6(21): 39-49.

xxxii. Ross, M. (2004). Art at the Crossroads: The Contested Position of Indigenous Arts in Ghana's Post-Colonial Education Systems. Studies in Art Education, 45(2): 117-134.

xxxiii. SCDCAC (2001). "The arts and culture in San Diego: economic impact report, 2000." San Diego, Calif.: City of San Diego Commission for Arts and Culture.

xxxiv. Smith, T. E. (1991). Agreement of adolescent educational expectations with perceived material and paternal educational goals.Youth and Society, 23: 155-174.

xxxv. Stanziola, J. (1999). Arts, government and community revitalization. Ashgate: Aldershot, U.K.; Brookfield, Vt. and Sydney.

xxxvi. Steers, R. (2011). Art and Design in Schools: Considerations and Challenges. Independent Schools Association Conference 2011,1-11.

xxxvii. STIMULA (2011). Stimulating Science and Technology competences through innovative means for teaching and learning. Accessed from https:// stimula.files.wordpress.com/.../ questionnaire-for-perceptionstudy_english1.pd...[21-06-15]

xxxviii. Turner, F. and Senior, P. (2000). A Powerful Force for Good: Culture, health and the arts- an anthology. Manchester: Manchester Metropolitan University.

xxxix. Watt, R. (2005). Attitudes to Making Art in the Primary School. 243-253.

xl. Weinger, S. (2000). Opportunities for career success: Views of poor and middle-class children. Children and Youth Services Review, 22 (1): 13-35.

xli. Williams, D. (1995). Creating social capital: a study of the long-term benefits from community based arts funding. Adelaide, S. Aust.: Community Arts Network of South Australia.

xlii. Wilson, P. M., \& Wilson, J. R. (1992). Environmental influences on adolescent educational aspiration: A logistic transform model.|| Youth \& Society, 24: 52-70.

xliii. Walesh, K. and Doug H. (2001). "The Creative Community--Leveraging Creativity andCultural Participation for Silicon Valley's Economic and Civic Future." San Jose, CA: Collaborative Economics. 